\title{
Responding to Change in Reproductive Endocrinology Fellowships
}

William Schlaff, MD

Jefferson Medical College

Follow this and additional works at: https://jdc.jefferson.edu/obgynfp

Part of the Obstetrics and Gynecology Commons

Let us know how access to this document benefits you

\section{Recommended Citation}

Schlaff, MD, William, "Responding to Change in Reproductive Endocrinology Fellowships" (2014). Department of Obstetrics and Gynecology Faculty Papers. Paper 30.

https://jdc.jefferson.edu/obgynfp/30

This Article is brought to you for free and open access by the Jefferson Digital Commons. The Jefferson Digital Commons is a service of Thomas Jefferson University's Center for Teaching and Learning (CTL). The Commons is a showcase for Jefferson books and journals, peer-reviewed scholarly publications, unique historical collections from the University archives, and teaching tools. The Jefferson Digital Commons allows researchers and interested readers anywhere in the world to learn about and keep up to date with Jefferson scholarship. This article has been accepted for inclusion in Department of Obstetrics and Gynecology Faculty Papers by an authorized administrator of the Jefferson Digital Commons. For more information, please contact: JeffersonDigitalCommons@jefferson.edu. 


\title{
As submitted to:
}

\author{
Fertility and Sterility
}

\author{
And later published as:
}

\section{Responding to Change in Reproductive Endocrinology Fellowships}

\author{
Volume 101, Issue 6, pages: 1510-1511, June 2014
}

\section{DOI: http://dx.doi.org/10.1016/j.fertnstert.2014.03.014}

William D. Schlaff, M.D.

Department of Obstetrics and Gynecology

Jefferson Medical College

834 Chestnut Street

Philadelphia, Pennsylvania 19107

william.schlaff@jefferson.edu

Thirty years ago, in the days when I was a reproductive endocrinology fellow, the field looked far different than it does today. Reproductive endocrinologists at that time were most assuredly the experts in diagnosing and treating infertility, but were often, if not usually the go-to doctors for patients with congenital uterovaginal anomalies, endometriosis, and those in need of complicated endoscopic procedures. The REI was not only the authority on polycystic ovary syndrome and other hormonal problems, but often the leader in addressing clinical issues in contraception, abnormal uterine bleeding, and menopause. In the early to mid-1980's infertility treatment, such as it was, was largely a surgical specialty. Many reproductive endocrinologists performed hundreds of operations per year, albeit with only modest success rates. There were less than 10 IVF programs in the country when I began my fellowship, and IUI was a new and novel treatment. The educational priorities of REI fellows reflected the practice at the time. We were trained primarily in reproductive surgery, medical and pediatric endocrinology, and to a lesser extent in the emerging field of ART.

The present role of the reproductive endocrinologist is tremendously different than it was then. Contemporary REI practice is mostly comprised of infertility treatment of which ART is obviously a huge component. The experience of our REI fellows as reported in the SREI Directory of Fellowship Programs (1) reflects this shift of focus. The median number of laparoscopies performed per fellow is 76 (range 7 to 407), median for laparotomies is 30 (range 7 to $111,25 \%$ did less than 10), and median for hysteroscopies is 90 (range 18-481). In the latter case it is not clear how many are simply screening procedures performed on asymptomatic women prior to IVF. The surgical experience of those completing minimally invasive surgery fellowships is far greater than this; it is now hard to argue that the REI is still the go-to endoscopist. Similarly, the authoritative voice in contraception clearly belongs 
to those who have completed fellowship training in family planning, and in many locales the diagnosis and treatment of young women with uterovaginal anomalies is now performed primarily by those trained in pediatric and adolescent gynecology. In addition, menopausal women as well as patients with PCOS and other routine reproductive endocrinologic disorders are increasingly cared for by "women's health specialists" in internal and family medicine.

What, then, does the future hold for the reproductive endocrinologist and REI fellow? This is clearly an unresolved question, discussed by many in our field. I believe that we can start to shape a potentially transformative response by focusing on where our expertise is most comprehensive and where we devote most of our clinical efforts, that is, in diagnosing and treating infertility. As our practice has evolved from straightforward treatments of women to include the care of gametes, embryos and even genes, it is in many ways no longer constrained by gender. Indeed, I am confident that many and perhaps most REI's are more knowledgeable about sperm and male reproduction and they are about many areas in obstetrics and gynecology. I propose that this expertise in reproduction could be further cultivated to improve our care of infertile couples by extending the practice of REl's to include the primary evaluation of infertile males. While recognizing that this notion might seem provocative or radical to some, I would suggest that such a practice, if properly developed, would represent a significant improvement over the present evaluation of many males which often consists of simply reviewing the results of a semen analysis. Routinely obtaining a detailed history and performing a thorough physical exam on the male partner is not common; indeed, it is not rare for physicians to recommend treatment of a male in the form of an IUI without ever having met him. Some men are routinely referred to a urologist for evaluation, but urologists trained in male infertility are few and far between, and it is my sense that general urologists usually do not have much interest in caring for these patients. Said simply, thorough evaluation of the male partner of an infertile couple is far from universal at present, and for this reason, significant issues affecting the fertility and health of the couple may be overlooked.

I would submit that with proper training, which could be incorporated into our existing fellowship programs, REI fellows and by extension REl's should be capable of routinely evaluating the partners of their female patients. We are better equipped to address hormonal issues in these patients than most general urologists, and could easily become facile in physical diagnosis, imaging, and in certain limited circumstances, performing relatively minor procedures. The REI seeing both partners would allow more comprehensive, efficient, and coordinated care of the infertile couple, and would likely be far more convenient for them. I do not intend in any way to disrespect or undervalue the outstanding expertise of our colleagues in urology who have been subspecialty-trained in male infertility. To the contrary, I would affirm that their expertise is critical to progress in our field, and their collaboration is tremendously important and appreciated by us and by our patients. However, many, and perhaps most REI's do not enjoy the luxury of an accessible subspecialty-trained expert. Indeed, even if such experts were available, would it not be better for them to see patients who were appropriately evaluated prior to referral? The purpose of this suggestion is not to threaten or usurp the role of the subspecialized urologist, but rather to evoke a collaborative training program along a "service line" model. Such a program could bear significant similarity to those that have been developed in the field of female pelvic medicine and reconstructive surgery.

The curricula of many of our present fellowships continue to emphasize a number of areas that play a relatively minor role in the practice of today's REI's. I believe we should redesign the clinical objectives and training of our young colleagues to help them become expert in what they will likely be doing when they have completed their fellowships. Learning to provide male infertility services would clearly 
represent a new direction in training REI fellows, and could lead to a more thorough reevaluation of our fellowship curricula. Perhaps the growing prominence of other related disciplines such as genetics might also replace traditional but increasingly less relevant fellowship objectives. Our esteemed Co-Editors of Fertility and Sterility have asked us to consider this "Inklings" forum as a chance to think out loud about important subjects. I hope that this is one to be considered.

\section{References:}

1) The American Society for Reproductive Medicine and the Society for Reproductive Endocrinology and Infertility, Inc. Directory of Fellowship Programs in Reproductive Endocrinology and Infertility; Fellowships Available in 2014. 